\title{
Utilization of dual contraception method among reproductive age women on antiretroviral therapy in selected public hospitals of Northern Ethiopia
}

Solomon Weldemariam Gebrehiwot ${ }^{2 *}$, Gedion Asnake Azeze ${ }^{1}$, Carmen C. Robles ${ }^{2}$ and Yohannes Mehretie Adinew ${ }^{1}$

\begin{abstract}
Background: Sexually transmitted infections are highly prevalent among pregnant women in Africa. Among the incidence of HIV infection in children, $90 \%$ of the infection is attributable to their mothers. Ethiopia is one of the countries with an increasing risky sexual behavior and the most affected by the HIV epidemic. If prevention of mother to child transmission focuses on increasing contraception, it will prevent more than 29\% of HIV infection at birth. Therefore, the aim of this study was to assess utilization of dual contraceptive method and associated factors among reproductive age women on antiretroviral therapy in selected public hospitals of Mekelle town, Northern Ethiopia.
\end{abstract}

Methods: Institution based cross-sectional survey was conducted in selected public hospitals of Mekelle among women under antiretroviral therapy from March 1-April 31, 2016. We used a systematic sampling technique to select 331 women. A pretested interviewer administered questionnaire was used for data collection. The data were entered in to Epi data version 3.1 and exported to SPSS version 20 for analysis. Bivariate and multivariable logistic regression analysis was computed. Odds ratio along with 95\% Cl was computed to ascertain the association. Statistical tests at $p$-value of $<0.05$ were considered as cut off point to determine statistical significance.

Results: Only 51(15.7\%) of participants have utilized dual contraception method. Being single[AOR 5.43, 95\% Cl (1. 61, 18.32)] and cohabitated [AOR 6.06; 95\% Cl: $(2.16,16.95)$ ] in marital status, having HIV negative partner [AOR 4.44; 95\% Cl: $(1.23,16.04)]$, exposure to post diagnosis counseling [AOR 3.03; 95\% Cl: 1.34, 6.80], disclosed HIV status [AOR 6.06; 95\% Cl: $(1.78,20.87)$ ] and discussing safer sex with partner [AOR 6.96; 95\% Cl: $(2.75,16.62)$ ] were positively associated with utilization of dual contraceptive method.

Conclusion: The overall magnitude of dual contraceptive use is still low in this study. This will be a great concern on the transmission of the virus from mother to babies and partners and risk of complications following unintended pregnancy. This will continue to present as major public health problems in the region unless future interventions focuses on the barriers through tailored counseling and husband involvement in all aspects of the HIV/AIDS care.

Keywords: HIV/AIDS, STIs, Dual contraceptive, Associated factors, Ethiopia

\footnotetext{
* Correspondence: mikiass1708@gmail.com

${ }^{2}$ Department of Midwifery, College of Health Science, Mekelle University, P.O.

Box 1871, Mekelle, Ethiopia

Full list of author information is available at the end of the article
} International License (http://creativecommons.org/licenses/by/4.0/), which permits unrestricted use, distribution, and reproduction in any medium, provided you give appropriate credit to the original author(s) and the source, provide a link to the Creative Commons license, and indicate if changes were made. The Creative Commons Public Domain Dedication waiver (http://creativecommons.org/publicdomain/zero/1.0/) applies to the data made available in this article, unless otherwise stated. 


\section{Plain English summary}

HIV positive mothers should give special emphasis in reproductive health care services since they are a special group in reproductive health care to maintain healthy generation in the future. Studies revealed that unintended pregnancy was significantly higher in HIV positive women $(20.7 \%)$ as compared to their counterparts (13.5\%). Therefore, the aim of this study is to explore the underlying associated factors with utilization of dual method contraception among reproductive age women on antiretroviral therapy. The study was conducted in two Hospitals from March 1 to 31, 2016. Systematic sampling technique was used to select study participants. The number of clients sampled from each hospital was proportional to the total number of client flow registered in the Antiretroviral Therapy (ART) unit. Data were collected by face to face interview technique using a structured questionnaire. Strength of association was determined using multivariable logistic regression model. Accordingly, Becoming single and cohabitated marital status, HIV status of partner, post diagnosis counseling, disclosure status and discussion with partner regarding safer sex were significantly associated factors. Hence, strengthening the counseling session and encouraging husband involvement during counseling sessions about contraception and STIs prevention strategies are highly recommended.

\section{Background}

More than 2 million HIV positive women become pregnant every year due to poor contraceptive utilization and unsafe sex practices, among them, 600,000 die of obstetric complications $[1,2]$.

Women who are on Highly Active Antiretroviral Therapy (HAART) and uses only highly effective contraceptive methods without condom, this circumstances will double the risk of acquisition of drug resistant strains of HIV-1 infection and twice as likely to pass the infection to their partners $[3,4]$. Although the increasing availability and use of HAART service has improved quality of life in people living with HIV (PLHIV), high total fertility rate (4.8\%), low contraceptive utilization (29\%) and significant proportion of mother to child transmission (MTCT) (30\%) were among the risk factors for HIV infection increment [5].

Studies revealed that unintended pregnancy was significantly higher in HIV positive women (20.7\%) as compared to their counterparts (13.5\%) [6]. Among the incidence of HIV infection in children, $90 \%$ of cases are attributable to mother to child transmission (MTCT) [7]. If prevention of mother to child transmission (PMTCT) focuses on increasing contraception, it will prevent more than $29 \%$ of HIV infection at birth [8]. By dual protection is a protection against both risks of unintended pregnancy and sexually transmitted infections
(STIs) including HIV [9, 10]. This dual objective could be achieved by using condom alone or the use of condom plus another effective contraceptive; like injectables, implants, pills, intrauterine contraceptive device(IUCD) (for those clinically stable or on Anti-Retroviral Therapy(ART)) and tubal sterilization in sexually active couples [11]. Moreover, it is also important to reduce pediatric HIV and obstetric complications following unintended pregnancy [3, 12-15]. Theoretically, dual protection can be accomplished by consistent use of male/female condom alone; however condom use alone as contraceptive method does not substantially decrease risk of pregnancy and in general it is not reliable method for women on ART $[16,17]$. It can only prevent up to $85 \%$ of unintended pregnancy $[11,18]$. On the other hand hormonal contraceptives, sterilization and intrauterine contraceptive device (IUCD) are effective in preventing unintended pregnancy as compared to condom but cannot prevent STIs including HIV $[16,18]$. The effectiveness of low-dose hormonal contraceptives may be reduced by ART drugs which necessitates the use of condom to compensate this gap [3]. Therefore, the best approach to dual protection is use of dual contraceptive methods [11].

Despite the obvious advantages, the United Nation Program on HIV/AIDS (UNAIDS) 2013, report has shown Ethiopia is one of the countries with an increasing risky sexual behavior and is most affected by the HIV epidemic [19]. Utilization of dual method contraception has been reported to be very low from research settings [3, 20]. Prevention of unintended pregnancy and sexual transmitted infections (STIs) including new strains of HIV infections among HIV positive women using condom plus another highly effective method is one of the 'cornerstones of a comprehensive program for PMTCT [21]. As far as our knowledge, many of the studies conducted previously in Ethiopia focused on contraceptive method utilization however studies on dual contraceptive method use were limited. The finding may contribute to increase knowledge and evidence on dual contraception method utilization in the country setting. Moreover, the results will be useful to public health policy makers and practitioners to restructure the service delivery system and formulate programs to reach the target group who are in need of dual method use. Therefore, the objective of this study was to assess utilization of dual contraception method and associated factors among reproductive age women on Anti Retroviral Therapy (ART) in selected public hospitals of Mekelle town, Northern Ethiopia.

\section{Methods}

Study setting and design

The study was conducted in two selected public hospitals of Mekelle town (Ayder comprehensive specialized 
hospital and Mekelle general hospital) the capital city of Tigray regional state located at the northern part of Ethiopia, about $783 \mathrm{~km}$ from Addis Ababa the capital city of Ethiopia. The major reason to consider these two hospitals as study area were, most people living with HIV/AIDS in Mekelle are attending at these two hospitals and they are the largest by' providing services from Mekelle town. In Ethiopia PMTCT related care is free of charge in public health facilities and most of the women prefer them as they can't afford the private ones. In addition, Ayder is a well equipped referral hospital for the entire Tigray region. However, the rest two public hospitals (Quiha, Semien Eiz hospital) and other public health centers have limited flow of patients. Moreover, a budget constraint was also another reason. Ayder comprehensive specialized hospital ART unit has given service for a total of 1117 clients since 2009, and Mekelle General Hospital has given service to 8669 ART users since 2003. Institution based cross sectional study was employed from March 1 to 31, 2016.

\section{Study population and sampling procedures}

The study population includes all HIV positive reproductive age women enrolled on ART units of the two hospitals. Women who were reproductive age group and sexually active in the past 3 months were eligible for this study. Pregnant women and women who were incapable to fertilize or reproduce for different reasons excluded from this study. A single population proportion formula $\left[\mathrm{n}=(\mathrm{z} \alpha / 2)^{2} \mathrm{p}(1-\mathrm{p}) / \mathrm{d}^{2}\right]$ was used to calculate the sample size with the assumption of $(26.7 \%)$ proportion of dual contraception use [22], 95\% confidence level, 5\% margin of error and $10 \%$ of non response rate. Overall, we recruited a total of 331 (223 respondents from Ayder referral hospital and 108 from Mekelle general hospital) respondents. The number of clients sampled from each hospital was proportional to the total number of eligible clients flow registered in the ART unit in 1 month by taking 3 months average of client flow. On average per a month, there were 354 eligible ART clients flow in Ayder comprehensive specialized hospital and 728 in Mekelle general hospital. We used systematic sampling technique to recruit every $\mathrm{k}^{\text {th }}$ eligible respondents and we used sequence/registration of client flow at outpatient department (OPD) as sampling frame. The value of " $k$ " was fortunately 3 for both hospitals. Lottery method was used to select the first participant by preparing 1 to 3 ranges of numbers then every subsequent participant was selected by skipping 2 clients until we fill the required sample size. Dual contraception method was defined as the use of male/female condom along with other highly effective contraceptive methods like pills, injectable, implants, sterilization (male/female) and intrauterine contraceptive device (IUCD) consistently in the last 3 months prior to the study. Use of condom alone as contraceptive method may not be effective to prevent unintended pregnancy. On the other hand, the other highly effective contraceptive methods are effective in preventing unintended pregnancy however they cannot prevent STIs including HIV. Moreover, condom is the only barrier method that can prevent STIs including HIV. Therefore, condom was taken as constant with other highly effective contraceptive methods.

\section{Data collection tool and procedures}

The questionnaire was adapted from published literatures and translated in to Tigrigna language (local language) then back to English language to check internal consistency. Four pre-service nursing students were collected the data by face to face interview technique using a structured questionnaire. A pre-test was conducted among 5\% (17 clients) of ART clients in Wukro hospital outside of Mekelle but with in similar set up. Appropriate modifications were made after analyzing the pretest result before the actual data collection. Data quality was assured by giving training and appropriate supervision for data collectors. Data collectors and supervisor were local language (Tigrigna) speakers. The overall supervision was carried out by the principal investigator and supervisors. The collected data were also cross checked on each day for its consistency and completeness.

\section{Data processing and analysis}

The collected data were checked for completeness and entered into Epi Data software version 3.1 and exported to SPSS window version 20 for data processing and analysis. Descriptive statistics like percent, mean and standard deviation were done. Both bivariate and multivariable logistic regression analysis were computed to identify associated factors. Odds ratio along with 95\% CI was computed to ascertain the association between independent and outcome variables. Variables that have $p$-value of $<0.2$ at bivariate analysis were included in multivariable logistic regression to control possible confounding factors. Statistical tests at $\mathrm{p}$-value of $<0.05$ were considered as cut off point to determine statistical significance.

\section{Ethical consideration}

Ethical clearance was obtained from the institutional ethical review board of Mekelle University, College of Health Sciences. Official letter of permission was written to the respective hospitals by Tigray Regional Health Office to Mekelle hospital and Medical director of the hospital to ART unit of Ayder referral hospital. Participants were informed about the purpose, benefit, risk, confidentiality of information and the voluntary nature of participation in the study. The interview was conducted in a private room. Data were collected after 
informed written consent was obtained from each participant that their interview data will be included in publications. For participants less than 18 years old, consent was taken from their parents/Guardian.

\section{Results}

Socio-demographic characteristics of respondents

Among the 331 sampled eligible respondents, 324 of them responded to the questionnaire completely, yielding a response rate of $97.9 \%$. The 7 non-responders were due to refusal to participate four and missed pages by the data collector during interview three. The mean age of the respondents was 32.49 years $(\mathrm{SD} \pm 6.21)$. Of the total respondents, majority of them were urban residents, 281(86.7\%), Tigrian in ethnicity, 269(83\%), followed by Amhara, 40(12.3\%), and others (Oromo and Afar), 15(4.7\%) (Table 1).

\section{Risk prevention behavior, access to information and reproductive characteristics}

Nearly half $157(48.5 \%)$ of the women had history of condom use and 97(61.8\%) of them were using it consistently. Reported reasons for not using condom were 74 (44.3\%) partners' refusal, 61(36.5\%) perceiving it as a barrier to sexual pleasure and $43(25.7 \%)$ being considering it ineffective. Almost half (48.5\%) of the respondents had one to two biologically alive child (median of 2.0 and IQR; 1, 3) (Table 2).

HIV disclosure and decision making status characteristics The participants median value of most recent CD4 count was 379 cells/dl (IQR; 261.50, 560.75 cells/dl). More than one third 125 (38.6\%) of study participants did not know their husband's/partner's HIV status. Among those women who were aware of their partner's HIV status, 42 (21.1\%) were sero-discordant (Table 3).

\section{Magnitude of dual contraceptive utilization}

Only 51(15.74\%) of women stated consistent use of dual contraception method. The most common form of dual method reported was condom combined with Injectable (68.6\%), implants (19.6\%), followed by pills (11.8\%). But no respondent has used condom plus intrauterine contraceptive device (IUCD) or sterilization method. Among the effective contraceptive users, the highest percentage was accounted by, 113 (34.9\%) Injectable, 54 (16.7\%) pills and 39 (12\%) implants.

\section{Factors associated with utilization of dual contraception method}

After controlling the effect of confounding variables, marital status, HIV status, post diagnosis counseling, disclosure status and free discussion with partner regarding safer sex were significantly associated with dual contraceptive
Table 1 Socio demographic variables of HIV positive women on ART in public Hospitals of Mekelle town, Ethiopia 2016

\begin{tabular}{|c|c|c|}
\hline Variables & Frequency (n) & Percent (\%) \\
\hline \multicolumn{3}{|l|}{ Age } \\
\hline $15-19$ & 9 & 2.9 \\
\hline $20-24$ & 21 & 6.5 \\
\hline $25-29$ & 61 & 18.8 \\
\hline $30-39$ & 187 & 57.6 \\
\hline $40-49$ & 46 & 14.2 \\
\hline \multicolumn{3}{|l|}{ Marital status } \\
\hline Married & 194 & 59.9 \\
\hline Married but separated & 34 & 10.5 \\
\hline Cohabitating & 50 & 15.4 \\
\hline Single & 46 & 14.2 \\
\hline \multicolumn{3}{|l|}{ Religion } \\
\hline Orthodox & 265 & 81.8 \\
\hline Muslim & 51 & 15.7 \\
\hline Protestant & 8 & 2.5 \\
\hline \multicolumn{3}{|l|}{ Occupation } \\
\hline House wife & 126 & 38.9 \\
\hline Merchant & 64 & 19.7 \\
\hline Daily laborer & 37 & 11.4 \\
\hline Government employee & 59 & 18.2 \\
\hline Student & 19 & 5.9 \\
\hline Others $^{a}$ & 19 & 5.9 \\
\hline \multicolumn{3}{|l|}{ Women's educational status } \\
\hline Illiterate & 88 & 27.2 \\
\hline Primary education & 109 & 33.6 \\
\hline Secondary education & 87 & 26.9 \\
\hline Tertiary education & 40 & 12.3 \\
\hline \multicolumn{3}{|c|}{ Husband's educational status } \\
\hline Illiterate & 45 & 13.8 \\
\hline Primary education & 86 & 26.5 \\
\hline Secondary education & 122 & 37.8 \\
\hline Tertiary education & 71 & 21.9 \\
\hline
\end{tabular}

Others ${ }^{\mathrm{a}}$ : Commercial sex workers, farmer and house servant

method. Accordingly, the odds of using dual contraceptive method was 5 [AOR 5.43, 95\% CI $(1.61,18.32)$ ] and 6 [AOR 6.06, CI $(2.16,16.95)]$ times higher among the single and cohabitated women respectively when compared to the married ones.

Partner's HIV status was an important predictor of dual contraceptive utilization. The odds of using dual contraceptive methods were about 4 [AOR 4.44, 95\% CI $(1.23,16.04)$ ] times higher among women whose partners were HIV negative when compared to those whose partner's status were unknown. Furthermore, the odds of using dual contraceptives methods were 3 [AOR 3.04, 95\% CI $(1.35,6.80)$ ] times 
Table 2 Risk prevention behavior, access to information and reproductive characteristics of HIV positive women on ART in public hospitals of Mekelle town, Ethiopia 2016

\begin{tabular}{|c|c|c|}
\hline Variables $N=324$ & Frequency (N) & Percent (\%) \\
\hline \multicolumn{3}{|l|}{ Use of condom } \\
\hline Yes & 157 & 48.5 \\
\hline No & 167 & 51.5 \\
\hline \multicolumn{3}{|l|}{ Consistency of condom use } \\
\hline Consistent & 97 & 61.8 \\
\hline Inconsistent & 60 & 38.2 \\
\hline \multicolumn{3}{|l|}{ Reasons to use condom ${ }^{a}$} \\
\hline To prevent STI/HIV & 100 & 63.7 \\
\hline To prevent pregnancy & 97 & 61.8 \\
\hline To prevent new HIV strain & 69 & 43.9 \\
\hline \multicolumn{3}{|l|}{ Reason for not using condom ${ }^{a}$} \\
\hline Refusal by partner & 74 & 44.3 \\
\hline Interruption of sexual pleasure & 61 & 36.5 \\
\hline Condoms ineffectiveness & 43 & 25.7 \\
\hline Religion & 42 & 25.1 \\
\hline Trust issues & 29 & 17.4 \\
\hline Breakage/slippage & 17 & 10.2 \\
\hline Fear of side effect & 12 & 7.2 \\
\hline Lack of access & 10 & 6.0 \\
\hline \multicolumn{3}{|l|}{ Post diagnosis counseling } \\
\hline Yes & 117 & 36.1 \\
\hline No/don't remember & 207 & 63.9 \\
\hline \multicolumn{3}{|l|}{ FP counseling by ART provider } \\
\hline Yes & 203 & 62.7 \\
\hline No/ don't remember & 121 & 37.3 \\
\hline \multicolumn{3}{|l|}{$\begin{array}{l}\text { Information where to get } \\
\text { contraception }\end{array}$} \\
\hline Yes & 225 & 69.4 \\
\hline No/ don't remember & 99 & 30.6 \\
\hline \multicolumn{3}{|l|}{$\begin{array}{l}\text { Prior experience of sexual } \\
\text { violence }\end{array}$} \\
\hline Yes & 78 & 24.1 \\
\hline No & 246 & 75.9 \\
\hline \multicolumn{3}{|l|}{ Number of alive child/children } \\
\hline None & 59 & 18.2 \\
\hline $1-2$ & 157 & 48.5 \\
\hline $3-4$ & 70 & 21.6 \\
\hline$\geq 5$ & 38 & 11.7 \\
\hline \multicolumn{3}{|l|}{ Future desire for more children } \\
\hline Yes & 208 & 64.2 \\
\hline No & 116 & 35.8 \\
\hline
\end{tabular}

${ }^{a}$ Respondents were allowed for more than one answer
Table 3 HIV disclosure and decision making status among HIV positive women on ART in public Hospitals of Mekelle town, Ethiopia, 2016

\begin{tabular}{|c|c|c|}
\hline Variables ( $N=324$ ) & Frequency (n) & Percentage (\%) \\
\hline \multicolumn{3}{|l|}{ Most recent CD4 count } \\
\hline$<250$ cells/dl & 74 & 22.9 \\
\hline 250-350 cells/dl & 73 & 22.5 \\
\hline$>350$ cells/dl & 177 & 54.6 \\
\hline \multicolumn{3}{|l|}{ Prior experience of TB infection } \\
\hline Yes & 89 & 27.5 \\
\hline No & 235 & 72.5 \\
\hline \multicolumn{3}{|l|}{ Disclosure of HIV status } \\
\hline Yes & 205 & 63.3 \\
\hline No & 119 & 36.7 \\
\hline \multicolumn{3}{|l|}{ To whom HIV disclosed? } \\
\hline To spouse/sexual partner & 102 & 31.5 \\
\hline To parents/family & 79 & 24.4 \\
\hline To the community as voluntary & 17 & 5.2 \\
\hline To friends & 7 & 2.2 \\
\hline \multicolumn{3}{|l|}{ Reason for not disclosing HIV status } \\
\hline Fear of stigma and discrimination & 41 & 34.5 \\
\hline Lack of trust on people & 29 & 24.3 \\
\hline Other & 49 & 41.2 \\
\hline \multicolumn{3}{|l|}{$\begin{array}{l}\text { Decision maker on women's sexual } \\
\text { and RH }\end{array}$} \\
\hline Her self & 171 & 52.8 \\
\hline together with husband & 136 & 42.0 \\
\hline Husband alone & 17 & 5.2 \\
\hline \multicolumn{3}{|l|}{ Free discussion with husband } \\
\hline Yes & 126 & 38.9 \\
\hline No & 198 & 61.1 \\
\hline
\end{tabular}

higher among women who had received post diagnosis counseling compared to their counterparts.

Women who had no desire for more children were 2 [AOR 2.65, 95\% CI $(1.16,6.07)]$ times more likely to use dual contraceptive method when compared to those who had desire. Compared to women who failed to disclose their HIV status, the odds of dual method use was 6 [AOR $6.08,95 \%$ CI $(1.77,20.87)]$ times higher among those who disclosed their status. Open discussion between partners was also strong predictor of dual contraceptive utilization. The odds of using dual contraception among women who had free discussion with their husband about safer sex were nearly 7 [AOR 6.96, 95\% CI $(2.75,17.62)$ ] times higher as compared to those who had none (Table 4).

\section{Discussion}

The uptake of dual contraceptive method was found to be very low. Marital status, HIV status, post diagnosis 
Table 4 Bivariate and multivariable logistic regression analysis of factors associated with dual contraception utilization among women on ART in public hospitals of northern, Ethiopia 2016

\begin{tabular}{|c|c|c|c|c|}
\hline \multirow[t]{2}{*}{ Variables } & \multicolumn{2}{|c|}{ Dual method utilization } & \multirow{2}{*}{$\begin{array}{l}\text { Crude OR (95\% } \\
\text { Cl) }\end{array}$} & \multirow{2}{*}{$\begin{array}{l}\text { Adjusted OR } \\
(95 \% \mathrm{Cl})\end{array}$} \\
\hline & No (\%) & Yes (\%) & & \\
\hline \multicolumn{5}{|l|}{ Age } \\
\hline $15-19$ & $7(77.8)$ & $2(22.2)$ & 1 & \\
\hline $20-24$ & $18(85.7)$ & $3(14.3)$ & $0.58(0.08,4.27)$ & \\
\hline $25-29$ & $43(70.5)$ & $18(29.5)$ & $1.46(0.27,7.74)$ & \\
\hline $30-39$ & $160(85.6)$ & $27(14.4)$ & $0.59(0.11,2.99)$ & \\
\hline $40-49$ & $45(97.8)$ & $1(2.2)$ & $0.07(0.01,0.97)$ & \\
\hline \multicolumn{5}{|l|}{ Marital status } \\
\hline Married & $173(89.2)$ & $21(10.8)$ & 1 & 1 \\
\hline Single & $33(71.7)$ & $13(28.3)$ & $3.24(1.47,7.11)$ & $5.43(1.61,18.32)^{*}$ \\
\hline Married but separated/ & $32(94.1)$ & $2(5.9)$ & $0.51(0.11,2.30)$ & $1.12(0.19,6.46)$ \\
\hline Cohabitating & $35(70.0)$ & $15(30.0)$ & $3.53(1.65,7.51)$ & $6.06(2.16,16.95)^{*}$ \\
\hline \multicolumn{5}{|l|}{ Women's education status } \\
\hline No formal education & $81(92.0)$ & $7(8.0)$ & 1 & \\
\hline Primary education & $100(91.7)$ & $9(8.3)$ & $1.04(0.37,2.91)$ & \\
\hline Secondary education & $65(74.7)$ & $22(25.3)$ & $3.91(1.57,9.74)$ & \\
\hline Tertiary and above & $27(67.5)$ & $13(32.5)$ & $5.57(2.01,15.40)$ & \\
\hline \multicolumn{5}{|l|}{ Husband's HIV status } \\
\hline Unknown & $115(92.0)$ & $10(8.0)$ & 12.49 & 1 \\
\hline HIV positive & $129(82.2)$ & $28(17.8)$ & $(1.16,5.36)$ & $0.72(0.22,2.33)$ \\
\hline HIV negative & $29(69.0)$ & $13(31.0)$ & $5.15(2.05,12.93)$ & $4.44(1.23,16.04)^{*}$ \\
\hline \multicolumn{5}{|l|}{ Post diagnosis counseling } \\
\hline No & $189(91.3)$ & $18(8.7)$ & 1 & 1 \\
\hline Yes & $84(71.8)$ & $33(28.2)$ & $4.12(2.19,7.73)$ & $3.03(1.35,6.8)^{*}$ \\
\hline \multicolumn{5}{|l|}{ Number of alive child } \\
\hline None & $47(79.7)$ & $12(20.3)$ & 1 & \\
\hline $1-2$ & $127(80.9)$ & $30(19.1)$ & $0.925(0.48,1.95)$ & \\
\hline $3-4$ & $64(91.4)$ & $6(8.6)$ & $0.367(0.12,1.04)$ & \\
\hline$>/=5$ & $35(92.1)$ & $3(7.9)$ & $0.336(0.08,1.28)$ & \\
\hline \multicolumn{5}{|l|}{ Future desire for more child } \\
\hline No & $90(77.6)$ & $26(22.4)$ & $2.11(1.15,3.86)$ & $2.65(1.16,6.07)^{*}$ \\
\hline Yes & $183(88.0)$ & $25(12.0)$ & 1 & 1 \\
\hline \multicolumn{5}{|l|}{ Disclosure of HIV status } \\
\hline No & $113(95.0)$ & $6(5.0)$ & 1 & 1 \\
\hline Yes & $160(78.0)$ & $45(22.0)$ & $5.29(2.19,12.84)$ & $6.08(1.77,20.87)^{*}$ \\
\hline \multicolumn{5}{|c|}{$\begin{array}{l}\text { Decision maker on women's } \\
\text { sexual and RH }\end{array}$} \\
\hline The respondent alone & $152(88.9)$ & $19(11.1)$ & 1 & \\
\hline The husband alone & $15(88.2)$ & $2(11.8)$ & $1.06(0.22,5.02)$ & \\
\hline Together & $106(77.9)$ & $30(22.1)$ & $2.26(1.21,4.23)$ & \\
\hline \multicolumn{5}{|l|}{ Free discussion } \\
\hline No & $189(95.5)$ & $9(4.5)$ & 1 & 1 \\
\hline Yes & $84(66.7)$ & $42(33.3)$ & $10.5(4.88,22.55)$ & $6.95(2.74,17.61)^{*}$ \\
\hline
\end{tabular}


counseling, disclosure status and discussion with partner regarding safer sex were significantly associated factors with utilization of dual contraceptive methods.

Dual method contraceptive utilization in the study area was found to be $51(15.7 \%)$ which is very low. This result is consistent with the findings from different parts of Ethiopia (Tigray region (14\%) [7], Addis Ababa (14.7\%) [8]), and South-Africa (14.4\%) [23]. However, the current finding is higher as compared to previous reports from rural Uganda and USA, where 3.5\% and 7.5\% of women used dual contraceptive method respectively [24, 25]. This might be due to an intervention that has been taking place in Ethiopia within the time gap since the time of the previous studies reported, where awareness creation about dual contraceptive method utilization is being advocated in Ethiopia. Currently, the government is expanding the family planning service and condom distribution including quality of service which might have increased dual contraceptive utilization.

On the contrary, the magnitude of dual method use in this study was lower when compared to studies conducted in Fitche, Ethiopia (32\%) [26], Southeast Nigeria (27.2\%) [27] and India (23\%) [11].The possible explanation for this difference might be partly due to the socio-demographic difference; plus the study from India includes men in their interview while the current study uses only women as study population. Men may have over reported non-barrier contraceptive use among their wives because the wives might not directly control condom use. Moreover, respondents from the India study were volunteer peer educators, thus, there might be sampling bias by recruiting more people educated about HIV and contraceptive use. Being single and is cohabiting increased the likelihood of utilizing dual contraception method as compared to married women. This result is consistent with findings from Ethiopia [28] and United state [25] which revealed that married women more practiced dual method less than single women. This might be due to the fact that husbands may resist use of condoms in marital and steady relationships because sex ought to be natural and based on trust. Furthermore, in Ethiopia people associate condom use as a method for preventing STIs and acknowledges the potential for infidelity and distrust within relationship and they perceived that having sex with their husband is a low risk for transmission [29]. This could limit the uptake of dual methods.

Women whose partners were HIV negative were more likely to use dual contraception method when compared to women whose partners' status were unknown. The finding is consistent with the findings from study conducted in India and France, where women whose partners were HIV negative were more likely to use dual contraceptive method as compared to their counter parts $[11,30]$. This might be due to the fact that those women who knows their partners' status are likely to be in committed relationships, therefore, able to negotiate condom use, and they might be more concerned for their sexual partners' health to use dual methods.

Receiving post diagnosis counseling was also predictor of dual contraception use. Respondents who received post diagnosis counseling were more likely to use dual contraceptive method compared to their counterparts. This finding is in line with study from India [11] that reported receiving post diagnosis counseling as a significant factor. This could be explained by the assumption that women could get advice on the importance of condom use in addition to other effective contraceptives, how to negotiate with sexual partner and risk reduction strategies.

Women who had no desire for more children showed better use of dual contraceptive method than those who had desire. The finding is in line with findings from Fitche, Ethiopia [26] and South Africa [8]. The possible reason is that fertility desire is obviously a proximate factor for dual method use. Moreover, these HIV positive women might realize that the probability of vertical transmission to their baby and the probability of obstetrical complications associated with pregnancy and delivery.

Respondents who disclosed their HIV status used dual contraceptive method more as compared to those who failed to disclose. This finding was supported with a study done in Addis Abeba, Ethiopia and Ghana [20, 28]. It could be due to the fact that, women who disclose their status to their sexual partner are expected to be more counseled and knowledgeable on safer sex practices which will help them to have free discussion in regard to sexual matters [31]. But, those who failed to disclose their status might not insist on condom use as they might be scared of exposing the secret they are hiding.

Another finding of the present study is that women who had free discussion with their husband showed better use of dual contraceptive method than their counterparts. The result is in agreement with the studies conducted in Tigray [32] and Addis Ababa Ethiopia [28]. This might be because these women are expected to have more freedom to negotiate safer sex and birth spacing. Similarly, positive effects of open discussion on couples contraception use have been widely demonstrated in different studies [22, 33].

\section{Conclusions and recommendations}

In spite of the fact that near half of the respondents in this study had history of condom use, the overall magnitude of dual contraceptive use is still low. It is an alarming message for developing countries; particularly to Ethiopia among the countries most affected by the HIV epidemic. This will be a great concern on the 
transmission of the virus from mother to babies, partners and obstetrical consequences following unintended pregnancy. This will continue to present as major public health problems in the region unless future interventions targeting on sexual activities and desire to have children. Hence, the efforts to increase dual method use should focus on strengthening the integration of family planning and HIV care service and encouraging tailored counseling and supportive care in the HIV/AIDS chronic care unit. Moreover, emphasis should be given to husband involvement in aspects of the HIV/AIDS care and disclosure status.

\section{Limitation of this study}

Despite the contribution of the study to provide knowledge and evidence of dual contraceptive use in PLHIV, this study has some limitations to be considered.

First, it is a cross-sectional study in which temporal relations could not be assessed.

Since this study is institutional based, the result of this study may not be generalizable to mothers attending health institutions outside the study area and found at community level. Furthermore, social desirability and stigma may have biased respondents and may not be generalizable to others found to be HIV positive women.

\section{Additional file}

Additional file 1: Dataset supporting data. (SAV $26 \mathrm{~kb}$ )

\begin{abstract}
Abbreviations
AIDS: Acquired immune deficiency syndrome; ART: Anti retroviral therapy; HAART: Highly active anti retroviral therapy; HIV: Human immune deficiency virus; IUCD: Intra uterine contraceptive device; MTCT: Mother to child transmission; PMTCT: Prevention of mother to child transmission; STI: Sexual transmitted disease; UNAIDS: United Nation program on HIV/AIDS
\end{abstract}

\section{Acknowledgements}

We are very grateful to thank Mekelle University for the financial support to this study and department of midwifery for its monitor ship. All study participants for their commitment in responding to our questionnaire.

\section{Funding}

This work has been funded by Mekelle University for data collection purpose as for MSc thesis. Mekelle University College of Health Sciences, department of midwifery was involved in the project through monitoring and evaluation of the work from the begging to the result submission. But this organization did not involve in designing, analysis, critical review of its intellectual content, preparation of manuscript and the budget funded by this organization did not include for publication. Ethical approval also assured through this organization.

\section{Availability of data and materials}

The dataset supporting the conclusions of this article is included with in the article and (its Additional file 1).

\section{Authors' contributions}

GA, SW, CCR and YM designed the study. GA prepared the proposal, obtained the data, analyzed and interpreted the data and obtained funding. SW, CCR and YM involved in analysis, reviewed and commented the entire of the paper from inception to end for its intellectual content. SW prepared the first draft of this manuscript. All authors reviewed, revised and approved the manuscript for publication.

Ethics approval and consent to participate

Ethical clearance was obtained from Institutional Ethical Review Board (IERB) of Mekelle University, College of Health Sciences. Official letter of permission was written to the respective hospitals by Tigray Regional Health Office to Mekelle hospital and Medical director of the hospital to ART unit of Ayder referral hospital. Informed written consent was obtained from study participants after explaining the objective of the study, the benefit and risks of participating in this study.

\section{Consent for publication}

It is not applicable.

Competing interests

The authors declare that they have no competing interests.

\section{Publisher's Note}

Springer Nature remains neutral with regard to jurisdictional claims in published maps and institutional affiliations.

\section{Author details}

${ }^{1}$ College of Health Sciences and Medicine, Wolaita Sodo University, Sodo, Ethiopia. ${ }^{2}$ Department of Midwifery, College of Health Science, Mekelle University, P.O. Box 1871, Mekelle, Ethiopia.

Received: 9 June 2017 Accepted: 26 September 2017

Published online: 05 October 2017

\section{References}

1. Oni EE, Ross A. Linde Svd. Contraceptive practices amongst HIV-positive women on antiretroviral therapy attending an ART clinic in South Africa. Afr J Prim Health Care Faily Med. 2013;5(1):1-6.

2. Inter-agency Task Team. Preventing HIV and unintended pregnancies: strategic framework 2011-2015. WHO, 2012. Available from: https://www.k4health.org/ sites/default/files/strategic_framework.pdf. [Cited on December 12/2015].

3. Agboghoroma CO. Contraception in the Context of HIV/AIDS: A review. Afr J Reprod Health. 2011;15(3):15-24.

4. Maraux B, Hamelin C, Bajos N, Dray-Spira R, Spire B, Lert F, Vespa study group. Women living with HIV still lack highly effective contraception: results from the ANRS VESPA2 study. Contraception. 2011;92(2015):160-9.

5. Workshop Group EC. Simultaneous prevention of unintended pregnancy and STls: a challenging compromise. Hum Reprod Update. 2014;20(6):952-63.

6. Muyindike W, Fatch R, Steinfield R, Matthews TL, Musinguzi N, Emenyonu IN, et al. Contraceptive use and associated factors among women enrolling into HIV care in Southwestern Uganda. Infect Dis Obstet Gynecol, Hindawi Publishing Corporation .2012; 2012:1-9. doi:https://doi.org/10.1155/2012/340782

7. Melaku YA, Zeleke EG. Contraceptive utilization and associated factors among HIV positive women on chronic follow up care in Tigray Region, Northern Ethiopia. PLoS One. 2014;9(4):e94682. https://doi.org/10.1371/ journal.pone.0094682.

8. Kaida A, Laher F, Strathdee SA, Money D, Janssen PA, Hogg SR, et al. Contraceptive use and method preference among women in soweto, South Africa: the influence of expanding access to HIV care and treatment services. PLoS One. 2010;5(11):e13868. https://doi.org/10.1371/journal.pone.0013868.

9. Marion WC, Hock-Long L, Kraft MJ, Henry-Moss D, Hatfield-Timajchy K, Merrill SM. Strategies for managing the dual risk of sexually transmitted infections and unintended pregnancy among Puerto Rican and African American young adults. Am J Public Health. 2012;102(3):449-56.

10. Jenny $A H$, Anne D. Cooper. Dual use of condoms and contraceptives in the USA. Sex Health. 2012;9(1):73-80. Available from: https://jennyahiggins.files. wordpress.com/2014/02/higgins-and-cooper-sex-health-2011-a-review-ofdual-method-use-in-the-us.pdf. [Cited on December 20/2015].

11. Venkatesan C, et al. Prevalence of and barriers to dual-contraceptive methods use among married men and women living with HIV in India. Infect Dis Obstet Gynecol, Hindawi Publishing Corporation. 2011;2011:1-8. https://doi.org/10.1155/2011/376432.

12. Lawani LO, Onyebuchi AK, lyoke CA. Dual method use for protection of pregnancy and disease prevention among HIV-infected women in South East Nigeria. BMC Womens Health. 2014;14:39. 
13. Federal Democratic Republic of Ethiopia Ministry of Health(FDRE MH). National guideline for family planning services in Ethiopia, 2011. Available from: http://phe-ethiopia.org/resadmin/uploads/attachment-158National_ Family_planning\%20guideline\%20.pdf. [Cited on December 4/ 2015].

14. Higgins AJ, Smith KN, Sanders AS, Schick V, Herb Nick D, Reece M, et al. Dual method use at last sexual encounter: A ntionally representative, episode-level analysis of US Men and Women. Contraception. 2014;90:399-406.

15. Department of Health, Republic of South Africa (2012). National contraception clinical guidline: a companion to the national contraception and fertility planning policy and service delivery guidline. December, 2012 Available from: https://www.health-e.org.za/wp-content/uploads/2014/05/ National-contraception-clinical-guidelines.pdf. [Cited on December 12/2015].

16. Schwartz SR, Rees H, Mehta S, Venter WD, Taha TE, Black V. High incidence of unplanned pregnancy after antiretroviral therapy initiation: findings from a prospective cohort study in South Africa. PLoS One. 2012;7(4):e36039.

17. WHO Guidelines Approved by the Guidelines Review Committee. Medical eligibility criteria for contraceptive use: A WHO Family Planning Cornerstone. 4th ed. Geneva: World Health Organization; 2010.

18. Wilson TE, Koenig LJ, Walter E, Fernandez I, Ethier K. Dual contraceptive method use for pregnancy and disease prevention among HIV infected and HIV uninfected women: the importance of an event-level focus for promoting safer sexual behaviors. Sex Transm Dis. 2003; 30(11):809-812. Pub Med Epub 2003/11/07.eng

19. UNAIDS. Global report: UNAIDS report on the global AIDS epidemic 2013. WHO Library Cataloguing, Geneva, Switzerland 2013. Available from: http://www. unaids.org/en/media/unaids/contentassets/documents/epidemiology/2013/ gr2013/UNAIDS_Global_Report_2013_en.pdf.[Cited on November 27/2015].

20. Gyimah AA, Nakua EK, Owusu-Dabo E, Otupiri E. Contraceptive characteristics of women living with HIV in the Kumasi Metropolis, Ghana. Int J MCH AIDS. 2013;2(1):111-20.

21. WHO HIV/AIDS Department. PMTCT strategic vision 2010-2015: preventing mother-to-child transmission of HIV to reach the UNGASS and Millennium Development Goals. Geneva: World Health Organization; 2010.

22. Kebede HG, Nahusenay H, Birhane Y, Tesfaye DJ. Assessment of contraceptive use and associated factors among HIV positive women in Bahir-Dar Town, Northwest Ethiopia. Open Access Library J. 2015;2:e1942. Available from: https://doi.org/10.4236/oalib.1101942

23. Patel NND, Newell ML, Coovadia HM, Rollins N, Coutsoudis A, Bland RM. Messages about dual contraception in areas of high HIV prevalence are not heeded. S Afr Med J. 2008;98(3):209-12.

24. Heys J, Kipp W, Jhangri GS, Alibhai A, Rubale T. Fertility desire and infections with the HIV: results from a survey in rural Uganda. AIDS Off J Int AIDS Soc. 2009;23(suppl 1):S37-45. https://doi.org/10.1097/01.aids.0000363776.76129.fd.

25. Eisenberg DL, Allsworth JE, Zhao Q, Peipert JF. Correlates of dual-method contraceptive use: an analysis of the national survey of family growth (2006-2008). Infect Dis Obstet Gynecol. 2012;2011:1-6. https://doi.org/10. $1155 / 2012 / 717163$

26. Demissie DB, Girma T, Abdissa G. Dual contraceptive utilization and associated factors among people living with HIV attending ART clinic in Fitche Hospital, Ethiopia. J Health, Med Nurs. 2015;20:2422-8419.

27. Udigwe GO, Mbachu II, Onyegbule OA, Oguaka V. Use of condoms among human immunodeficiency virus positive women attending antenatal clinic in Nnewi, South East Nigeria. Annal Med Health Sci. 2014;4(5):687-91.

28. Asfaw HM, Gashe FE. Contraceptive use and method preference among HIV positive women in Addis Ababa. Ethiopia BMC Public Health. 2014;14:566.

29. Tsigemariam T, Gail D. Which factors influence north Ethiopian adults'use of dual protection from unintended pregnancy and HIV/AIDS? Ethiop J Health Dev. 2008:22(3):226-31.

30. Heard I, Potard V, Costagliola D, Kazatchkine MD. Contraceptive use in HIV-positive women. J Acquire Immune Deficiency Syndrom. 2004;36(2):714-20.

31. Sara ES, et al. Contraception use among Iranian women with HIV: a qualitative study. Global J Health Sci. 2016;8(1):1916-9736.

32. Berhane $Y$, Berhe $H$, Abera GB, Berhe H. Utilization of modern contraceptives among HIV positive reproductive age women in Tigray, Ethiopia. ISRN AIDS. 2013;2013:1-8. https://doi.org/10.1155/2013/319724.

33. Rhoda KW, et al. Fertility and contraceptive decision-making and support for HIV infected individuals: client and provider experiences and perceptions at two HIV clinics in Uganda. BMC Public Health. 2013;13:98.

\section{Submit your next manuscript to BioMed Central and we will help you at every step:}

- We accept pre-submission inquiries

- Our selector tool helps you to find the most relevant journal

- We provide round the clock customer support

- Convenient online submission

- Thorough peer review

- Inclusion in PubMed and all major indexing services

- Maximum visibility for your research

Submit your manuscript at www.biomedcentral.com/submit
C Biomed Central 